Research Paper

\title{
Glypican-1 as a Biomarker for Prostate Cancer: Isolation and Characterization
}

\author{
Quach Truong, Irene O. Justiniano, Aline L. Nocon, Julie T. Soon, Sandra Wissmueller, \\ Douglas H. Campbell and Bradley J. Walsh ${ }^{\bowtie}$
}

Minomic International Ltd, Suite 2, Ground Floor, 75 Talavera Rd, Macquarie Park, NSW 2113, Australia

$\triangle$ Corresponding author: Dr Bradley J. Walsh, Email: brad.walsh@minomic.com, Phone: +61 298504000

(C) Ivyspring International Publisher. Reproduction is permitted for personal, noncommercial use, provided that the article is in whole, unmodified, and properly cited. See http://ivyspring.com/terms for terms and conditions.

Received: 2015.12.10; Accepted: 2016.03.22; Published: 2016.05.21

\begin{abstract}
Prostate cancer is the most frequently diagnosed male visceral cancer and the second leading cause of cancer death in the United States. Standard tests such as prostate-specific antigen (PSA) measurement have poor specificity $(33 \%)$ resulting in a high number of false positive reports. Consequently there is a need for new biomarkers to address this problem. The MIL-38 antibody was first described nearly thirty years ago, however, until now, the identification of the target antigen remained elusive. By a series of molecular techniques and mass spectrometry, the MIL-38 antigen was identified to be the highly glycosylated proteoglycan Glypican-1 (GPC-1). This protein is present in two forms; a membrane bound core protein of 55-60 kDa and secreted soluble forms of $40 \mathrm{kDa}$ and $52 \mathrm{kDa}$. GPC-1 identification was confirmed by immuno-precipitation, western blots and ELISA. An ELISA platform is currently being developed to assess the levels of GPC-1 in normal, benign prostatic hyperplasia (BPH) and prostate cancer patients to determine whether secreted GPC-1 may represent a clinically relevant biomarker for prostate cancer diagnosis.
\end{abstract}

Key words: Prostate Cancer, Glypican 1, Proteoglycan, Theranostic

\section{Introduction}

Many potential prostate cancer biomarkers have been identified to assist in the diagnosis and prognosis of the disease ${ }^{1}$. As prostate cancer is the most frequently diagnosed male visceral cancer and the second leading cause of cancer death in the United States it is unsurprising that there has been such a broad effort. The American Cancer Society estimates that in 2015 about 220800 new cases of prostate will be diagnosed and 27540 men will die of the disease.

Digital rectal exam (DRE) and measurement of PSA in the blood of patients are the two major prostate cancer detection tests currently used by medical professionals. Unfortunately, neither of these tests are entirely conclusive and both can result in false negatives (leaving real cancers undetected), and false positives (signalling cancer where there is none). In fact, the poor specificity ( $33 \%$ ) exhibited by the PSA test has led to controversy about how and when it should be used 2,3 . Consequently, a number of biomarkers have been developed as companion diagnostics to improve the PSA test $t^{4,5}$. Multianalyte tests such as the PHI test (measuring three different PSA markers: PSA, free PSA and p2PSA) ${ }^{6}$ and the OPKO $4 \mathrm{~K}$ score (measuring four prostate-specific kallikreins $)^{7}$ have improved the sensitivity of the PSA test but specificity still remains poor. As one of the most powerful tools against cancer is early accurate detection, the search continues for biomarkers that will help to address this issue.

Cell surface markers of disease have potential to be theranostics, that is, they have both diagnostic and therapeutic applications. There is likelihood that such surface molecules will be shed into the body fluids, thus allowing their measurement in a non-invasive fashion. In situ antibodies or aptamers to cell surface molecules can be used to target the location of tumors using medical imaging and to deliver toxic payloads to the tumor in the form of radio-immunotherapy or 
antibody drug conjugates ${ }^{8,9}$.

The MIL-38 monoclonal antibody, previously known as BLCA-38, was originally raised to a primary bladder cancer tumor ${ }^{10,11}$. MIL-38 showed specific binding to prostate cancer cell lines and prostate cancers, with no reactivity to normal prostate or other normal tissues tested ${ }^{12}$. The MIL-38 antigen therefore represents a potential theranostic marker for prostate cancer. This paper describes for the first time the identity of the MIL-38 antigen as the cell surface antigen Glypican-1.

\section{Materials and Methods}

\section{DU-145 and C3 cell lines}

The prostate cancer cell line DU-145 cells were purchased from ATCC. Antigen negative C3 cells ${ }^{12}$ were kindly provided by Professor Pamela Russell (Australian Prostate Cancer Research Centre, Institute of Health and Biomedical Innovation, Queensland University of Technology, Australia). MIL-38 hybridomas were provided by Professor Pamela Russell and also obtained from the ATCC. Cells were cultured according to standard tissue culture techniques at $37^{\circ} \mathrm{C}$ with $5 \% \mathrm{CO}_{2}$. DU-145 cells were grown in RPMI-1640 medium supplemented with 10\% Newborn Calf Serum (NCS) and C3 cells in RPMI-1640 supplemented with 20\% Foetal Bovine Serum (FBS) in T175 flasks (Greiner Bio-one, Frickenhausen, Germany). To harvest conditioned media, cells were grown in RPMI in the absence of NCS for 24 to $48 \mathrm{~h}$. For scale up and harvest, cells were briefly washed with PBS and detached using $2 \mathrm{mM}$ EDTA in PBS at $37^{\circ} \mathrm{C}$ for $15 \mathrm{~min}$. Cells were resuspended in PBS and kept on ice until required.

\section{MIL-38 production}

Frozen hybridoma cell stocks were thawed followed by resuspension in RPMI-1640 medium (Life Technologies, Carlsbad, California, US) and allowed to grow at $37^{\circ} \mathrm{C}$ with $5 \% \mathrm{CO}_{2}$ for $72 \mathrm{~h}$. Cells were expanded, split and scaled up in a sequential process. At each step, cells were resuspended in fresh medium and incubated at $37^{\circ} \mathrm{C}$ with $5 \% \mathrm{CO}_{2}$. After scale up, cells were transferred to sterile serum-free medium and grown till the start of death phase. The supernatant was harvested to collect the MIL-38 antibody, filter sterilized and stored at $-80^{\circ} \mathrm{C}$ until required. Antibody was purified using Pierce Protein G Agarose (Thermofisher Scientific, Waltham Massachusetts, US) according to the manufacturer's recommendations.

\section{Antibodies and proteins used}

MIL-38 antibody was produced in-house as described above. Rabbit anti-GPC1 antibody was purchased from Abcam (Cat no. PN000-06211, Cambridge, UK). A recombinant GPC-1 protein produced in murine NS0 cells was purchased from R\&D Systems (Cat no. 4519-GP, Minneapolis, Minnesota, US).

\section{Flow cytometry}

Detached cells were counted and aliquoted to a concentration of $2 \times 10^{5}$ cells per sample. Primary antibody (MIL-38) and secondary antibodies were prepared in Wash Solution (5\% FBS in PBS). Cells were incubated with MIL-38 $(2 \mu \mathrm{g}$ in $50 \mu \mathrm{L})$ at $4^{\circ} \mathrm{C}$ for $45 \mathrm{~min}$ followed by three washes with Wash Solution. Goat anti-mouse Alexa Fluor ${ }^{\circledR} 488$ (Life Technologies: $2 \mu \mathrm{g}$ in $50 \mu \mathrm{L}$ ) secondary antibody incubations were performed at $4^{\circ} \mathrm{C}$ for $30 \mathrm{~min}$ in the dark followed by three washes in Wash Solution. The cells were stored as a pellet on ice until flow cytometric analysis. Samples were run on a BD LSR Fortessa X-20 (Becton, Dickinson and Company, Franklin Lakes, New Jersey, US). All parameters were set to $\log$ scale at the following voltages: FSC: 115. SSC: 88, Alexa Fluor 488: 280.

\section{Protein Extraction, SDS PAGE and Western Blot Analysis}

Membrane proteins were extracted from DU-145 and C3 cells using the ProteoExtract Native Membrane Protein Extraction Kit (MPEK: Merck Millipore, Darmstadt, Germany) according to manufacturer's instructions. Extracted proteins were mixed with non-reducing SDS sample buffer unless specified and loaded onto $4-15 \%$ precast Criterion TGX (Tris-Glycine) gels (Bio-Rad, Hercules, California, US). Gels were run for $10 \mathrm{~min}$ at $80 \mathrm{~V}$ and additional $50 \mathrm{~min}$ at $200 \mathrm{~V}$ in Tris-Glycine running buffer. Proteins were transferred to nitrocellulose membranes (Bio-Rad) using the Transblot Turbo system (Bio-Rad). Transfer was at 2.5A, 25V maximum for $10 \mathrm{~min}$.

For visualisation, all incubations were performed at room temperature. Gels were fixed with staining/destaining solution $(10 \%$ Ethanol, $7 \%$ acetic acid) for $2 \mathrm{~h}$ followed by overnight incubation with SyproßRuby (Thermofisher Scientific) in the dark. Gels were rinsed and washed with destaining solution for a minimum of $2 \mathrm{~h}$. Imaging was performed with a Pharos X Scanner (Bio-Rad). If required, gels were post stained with Bio-Safe ${ }^{\mathrm{TM}}$ Coomassie (Bio-Rad).

Western blot was performed by blocking the membranes with 5\% skim milk in PBS-0.1\% Tween-20 for $2 \mathrm{~h}$ at room temperature. MIL-38 or rabbit anti-GPC-1 antibodies $(1 \mu \mathrm{g} / \mathrm{ml}$ in $5 \%$ skim milk PBS- $0.1 \%$ Tween) were applied and incubated 
overnight at $4^{\circ} \mathrm{C}$. The primary antibody was omitted for negative controls. After washing $(3 \times 10 \mathrm{~min}$ PBS- $0.1 \%$ Tween) membranes were incubated with either 1:2,000 sheep-anti-mouse HRP-labelled secondary antibody (GE Healthcare Life Sciences, Cleveland, Ohio, US) or 1:2,000 goat anti-rabbit HRP labelled secondary antibody (Abcam) in 5\% skim milk - PBS-0.1\% Tween for $1 \mathrm{~h}$ at room temperature. After washing ( $3 \times 10$ min PBS-0.1\%Tween) antigen was detected using ECL detection kit (Bio-Rad) and imaged with a LAS4000 mini imager (GE Healthcare Life Sciences).

Protein expression levels were quantified by using Image J (National Institutes of Health, Bethesda, Maryland). Comparative protein bands were individually selected and the area measured for each band.

\section{Two dimensional PAGE}

Membrane protein lysates $(180 \mu \mathrm{g})$ were desalted using 7M Urea, 2M thiourea in 3,000 MWCO spin columns (Sartorius AG, Göttingen, Germany) until conductivity was $210 \mu \mathrm{S}$. Four percent CHAPS $(\mathrm{w} / \mathrm{v})$ and bromophenol blue was added. Samples were spun at $20000 \times g$ to remove precipitates and used to rehydrate pI 3-10 IPG strips (Bio-Rad) overnight. Isoelectric focusing (IEF) was performed at $500 \mathrm{~V}$ for $1 \mathrm{~h}$ (step and hold), 100V for $1 \mathrm{~h}$ (gradient), 8 $000 \mathrm{~V}$ for $3 \mathrm{~h}$ (gradient) and $8000 \mathrm{~V}$ for a further $3 \mathrm{~h}$ (step and hold). IPG strips were then equilibrated twice with non-reducing solution (2\% SDS, 6M Urea, $20 \%$ glycerol, $0.375 \mathrm{M}$ Tris- $\mathrm{HCl}, \mathrm{pH} 8.8$ ). Strips were run on precast $4-15 \%$ TGX gels (Bio-Rad) at $50 \mathrm{~V}$ for 10 min followed by $200 \mathrm{~V}$ for $1 \mathrm{~h}$.

\section{Immuno-precipitation}

Dynabeads (Life Technologies, Cat no. 14311D)

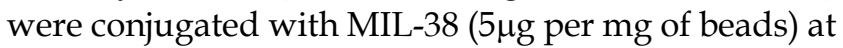
$37^{\circ} \mathrm{C}$ overnight as per manufacturer's instructions. The conjugated beads were then washed and incubated with membrane protein extracts at $4^{\circ} \mathrm{C}$ overnight. Prior to gel running or mass spectrometry, captured antigen was eluted using a low $\mathrm{pH}$ buffer (0.2M glycine, $\mathrm{pH} 3.5,0.5 \%$ Triton- $X 100)$ for $5 \mathrm{~min}$ followed by neutralization (1M Tris- $\mathrm{HCl}, \mathrm{pH} 9.0)$.

Immuno-precipitations were performed as above with a commercial rabbit anti-GPC-1 antibody. This antibody was used for all confirmatory and comparative analysis.

\section{Antigen selection and Mass Spectrometry}

Antigen was immuno-precipitated from DU-145 extracts, eluted with low $\mathrm{pH}$ buffer, then run on two parallel gels. One gel was processed using the western blot procedure and the other run and stained by SyproßRuby and Coomassie Blue. The western blots were used as a reference to confirm recognition of MIL-38 to the antigen. Bands were cut blind from stained gels for mass spectrometry using molecular weight markers as a guide. Gel bands were destained, reduced (25 mM DTT) and alkylated (55 mM iodoacetamide (IAA) in $25 \mathrm{mM}$ ammonium bicarbonate), dried, then digested with trypsin in ammonium bicarbonate $(\mathrm{pH} \mathrm{8)}$ overnight. Peptides were extracted with acetonitrile $(\mathrm{ACN})$ :water:formic acid (50:45:5) then vacuum concentrated.

For gel free analysis, immuno-precipitated antigen was reduced for $30 \mathrm{~min}$ at $65^{\circ} \mathrm{C}$ in $10 \mathrm{mM}$ DTT in $7 \mathrm{M}$ urea, $2 \mathrm{M}$ thiourea in water. Proteins were alkylated with $55 \mathrm{mM}$ IAA in $100 \mathrm{mM}$ ammonium bicarbonate for $20 \mathrm{~min}$ in the dark. Liquid samples were diluted 1:10 with $25 \mathrm{mM}$ ammonium bicarbonate, followed by overnight TPCK trypsin (500 ng) digestion at $37^{\circ} \mathrm{C}$. Peptides were extracted with ACN:water:formic acid (50:45:5) then vacuum concentrated.

For mass spectrometry, sample $(10 \mu \mathrm{L})$ was injected onto a peptide trap column (Michrome peptide Captrap) for pre-concentration and desalted with $0.1 \%$ formic acid, $2 \%$ acetonitrile, at $5 \mu \mathrm{L} / \mathrm{min}$ for 10 minutes. The peptide trap column was then switched into line with the analytical column. Peptides were eluted from the column using a linear gradient from $\mathrm{H}_{2} \mathrm{O}$ :ACN $(98: 2 ;+0.1 \%$ formic acid) to $\mathrm{H}_{2} \mathrm{O}: \mathrm{ACN}(10: 90 ;+0.1 \%$ formic acid) at $1 \mu \mathrm{L} / \mathrm{min}$ over a $120 \mathrm{~min}$ period. The eluent was subject to positive ion nanoflow electrospray MS analysis in an information dependent acquisition mode (IDA). In the IDA mode a TOFMS survey scan was acquired $(\mathrm{m} / \mathrm{z}$ 350-1200, $0.5 \mathrm{sec})$, with the ten largest multiply charged ions (counts >150) in the survey scan sequentially subjected to MS/MS analysis. MS/MS spectra were accumulated for 100 milli-seconds $(\mathrm{m} / \mathrm{z}$ 100-1500) with rolling collision energy. Peak lists generated were then searched using Mascot (Matrix Science, Boston, Massachusetts, USA) against Homo sapiens proteins to identify the antigen.

\section{Results}

\section{Flow cytometric analysis of MIL-38 binding}

Prostate cancer DU-145 and C3 negative control cells were indirectly labelled with MIL-38 and analysed by FLOW cytometry. MIL-38 recognised a surface antigen of DU-145 cells with a two log increase over C3 cells (Figure 1). Secondary antibody controls only were used as the baseline. These results were consistent with those reported previously ${ }^{12}$. 


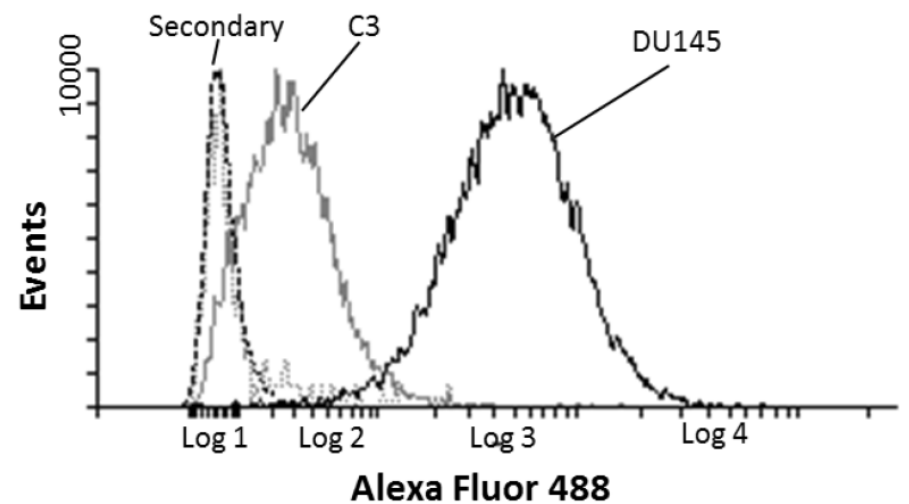

Figure 1. Flow cytometric analysis of MIL-38 binding to the surface antigen on DU-145 and C3 cells. The secondary antibody only control (DU-145 (dash) and C3 (dotted) cells) represents the baseline of the analysis. DU-145 cells show strong staining and C3 cells represent a negative population sample.

A

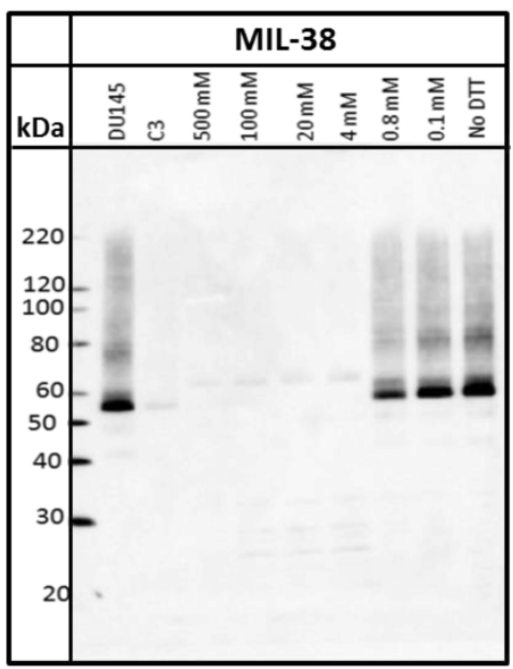

B

\begin{tabular}{|c|c|c|c|}
\hline & \multicolumn{3}{|c|}{ MIL-38 } \\
\hline kDa & A & B & C \\
\hline 120 & & & \\
\hline 100 & & & \\
\hline 80 & & & \\
\hline 60 & & & \\
\hline 50 & & & \\
\hline 40 & & & \\
\hline 30 & & & \\
\hline 20 & & & \\
\hline
\end{tabular}

$\mathrm{C}$

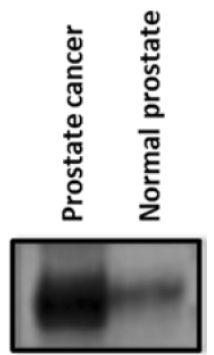

Figure 2. A. Western Blot of DU-145 membrane protein extracts treated with increasing concentrations of DTT. DU-145 (Lane 1) and C3 (Lane 2) are positive and negative controls respectively. B. Western Blot of immuno-precipitated of DU-145 membrane protein extracts (Lane A). The solid arrow indicates the immuno-precipitated antigen and the outlined arrow indicates the MIL-38 antibody. Antigen is not immuno-precipitated in Lanes (B) representing protein extracts with unconjugated beads or Lane (C) which represents antibody conjugated beads with no protein extracts. C. Western blot of membrane protein extracts from prostate cancer and normal prostate samples. The prostate cancer sample shows strong reactivity with MIL-38 at thirty times more expression than normal prostate samples.

\section{Characterization of the membrane associated MIL-38 antigen.}

Western blots of DU-145 membrane extracts indicated that MIL-38 recognized a protein band of between 55-60 kDa under non-reduced conditions (Figure 2A). Increasing the concentration of dithiothreitol (DTT) in the sample buffer resulted in decreased binding of MIL-38 to the antigen. Reactivity was lost if DTT concentration was greater than $0.8 \mathrm{mM}$. These results indicate that the MIL-38 epitope is reduction sensitive and the epitope is most likely a structural determinant.

MIL-38 immuno-precipitations of DU-145 membrane extracts followed by MIL-38 western blotting also detected the $55-60 \mathrm{kDa}$ antigen (Figure 2B). In the absence of either conjugated beads or protein lysate, no antigen was captured (negative controls). No antigen was detected in C3 protein lysates and C3 immuno-precipitated precipitated extracts (results not shown).

To determine if the MIL-38 antigen could be detected in membrane protein extracts from normal prostate and prostate cancer, one sample of each was obtained from Novus Biologicals (Littleton, Colorado, USA). Equivalent amounts of protein were western blotted using MIL-38 antibody (Figure 2C). The prostate cancer extract demonstrated thirty times more protein expression of the MIL-38 antigen than the normal prostate sample.

\section{MIL-38 can detect antigen secreted into cell culture supernatant.}

Conditioned serum-free media from DU-145 cells was harvested and immuno-precipitated with MIL-38 conjugated beads. A standard 
immuno-precipitation from DU-145 membrane protein extracts was run for comparison. For the serum free medium, bands of approximately 40 and 50-52 $\mathrm{kDa}$ were observed on the Western blot, compared to the $55-60 \mathrm{kDa}$ band isolated from DU-145 membrane protein extracts (Figure 3).

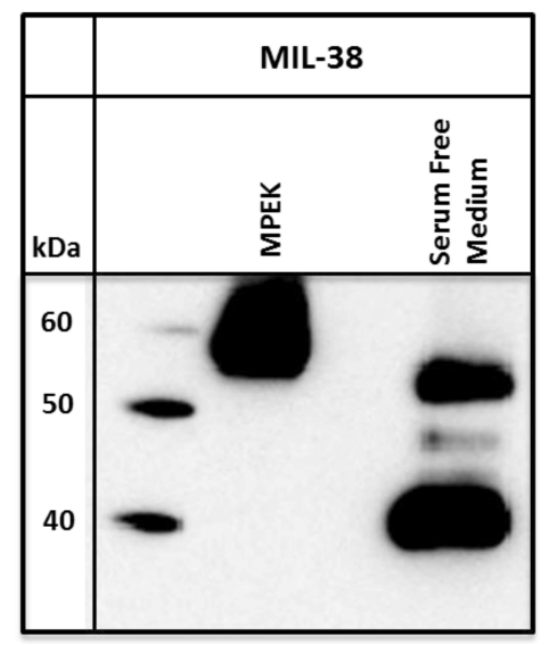

Figure 3. Western blot of MIL-38 antigen secreted into conditioned serum free medium by DU-145 cells. Two proteins of sizes $40 \mathrm{kDa}$ and $52 \mathrm{kDa}$ were identified. DU-145 membrane protein extracts (MPEK) immuno-precipitates were run as controls and show the $55-60 \mathrm{kDa}$ antigen.

\section{Identification of the MIL-38 antigen by mass spectrometry.}

To identify the MIL-38 antigen by mass spectrometry, DU-145 immuno-precipitates were processed in two ways. The immuno-precipitates were eluted ('gel free') and subjected to mass spectrometry. Alternatively, the immuno-precipitates were run on two identical gels; a western blot was performed using one gel and this was used to approximate the location of the band corresponding to the antigen. A region of the gel pertaining to the antigen was excised from the second gel and then subjected to mass spectrometry. Band excision was performed for the $40 \mathrm{kDa}$ and $52 \mathrm{kDa}$ secreted antigen. Control samples were analyzed in similar manners.
Analysis of the mass spectrometry data using Mascot identified the MIL-38 antigen as Glypican-1 (GPC-1; Swissprot P35053). Samples were either excised from gels $(n=4)$ or directly eluted $(n=2)$ prior to analysis. The highest peptide score of 4278 represents 18 distinct peptide sequences covering $46 \%$ of the GPC-1 sequence (Figure 4). GPC-1 was not detected in any of the control samples (MIL-38 conjugated Dynabeads alone or DU-145 extracts incubated with unconjugated Dynabeads).

The MIL-38 antigens from the $40 \mathrm{kDa}$ and $52 \mathrm{kDa}$ bands were also identified as GPC-1. The $40 \mathrm{kDa}$ band (Table 1) identified 48 peptides with sequence coverage of $18 \%$. The $52 \mathrm{kDa}$ band (Table 1) identified 39 peptides with sequence coverage of $24 \%$. These results suggest that a MIL-38-reactive form of GPC-1 can be released into cell culture supernatant from the DU145 prostate cancer cell line.

Table 1. Identification of the MIL-38 antigen (GPC-1) by various characterization experiments. Scoring is based on the number of peptides isolated and the frequency using the MASCOT protein database

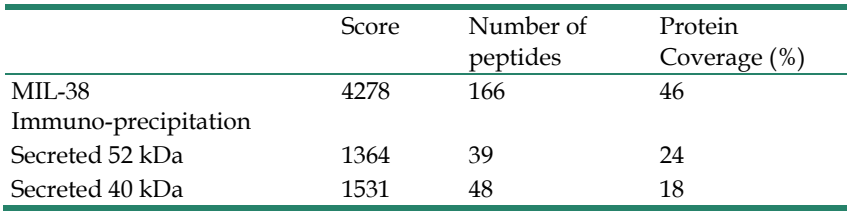

\section{Confirmation of the MIL-38 antigen as GPC-1}

A commercial rabbit anti-GPC-1 was used to probe MIL-38 immuno-precipitates and DU-145 membrane extracts. The antibody detected an antigen of $\sim 60 \mathrm{kDa}$ in both DU-145 membrane extracts and also in the MIL-38 immuno-precipitates. Similarly, rabbit anti-GPC-1 immuno-precipitates probed with MIL-38 identified the same size $60 \mathrm{kDa}$ antigen (Figure 5) and extracts showed almost complete depletion of the $60 \mathrm{kDa}$ antigen following immuno-depletion with either antibody.

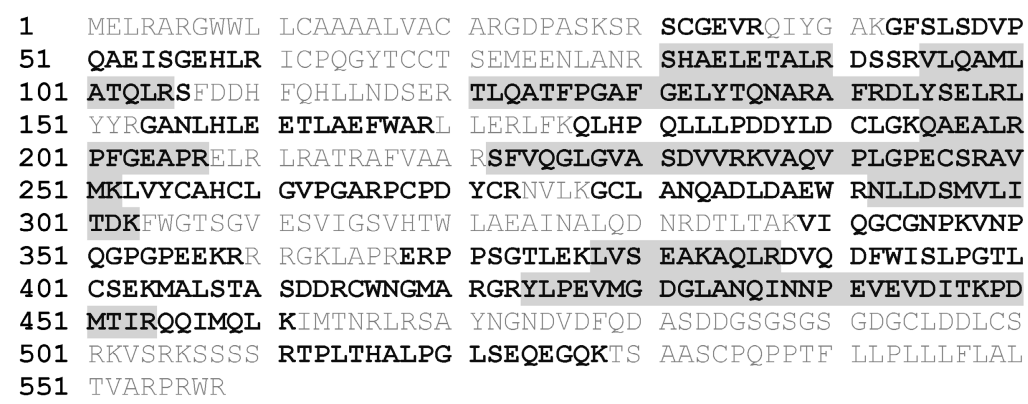

Figure 4. Mass spectrometric identification of the MIL-38 antigen (GPC-1). Identified amino acids are in bold ( $78 \%$ coverage). Amino acids identified in the secreted form are highlighted in grey. 


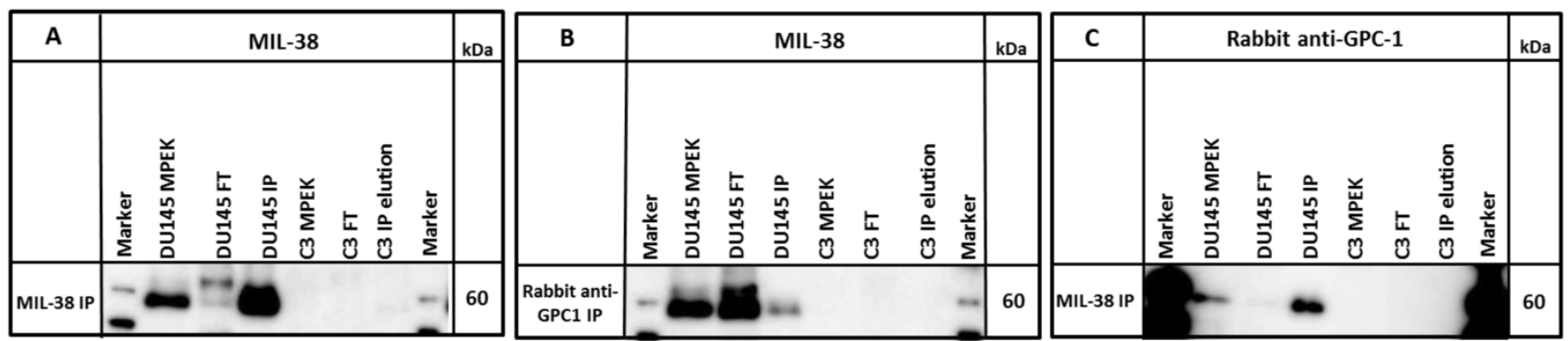

Figure 5. Western blot of immuno-precipitates (IP) of MIL-38 or rabbit anti-GPC-1 conjugated beads with DUI 45 or C3 protein lysates (MPEK). DUI45 protein lysates were immuno-precipitated by MIL-38 (A, C) and rabbit anti-GPC-1 (B) and probed by MIL-38 (A, B) or rabbit anti-GPC-1 (C). C3 protein lysates were not immuno-precipitated by either antibody. FT (flow through) is defined as the proteins in the supernatant not captured by the conjugated beads.

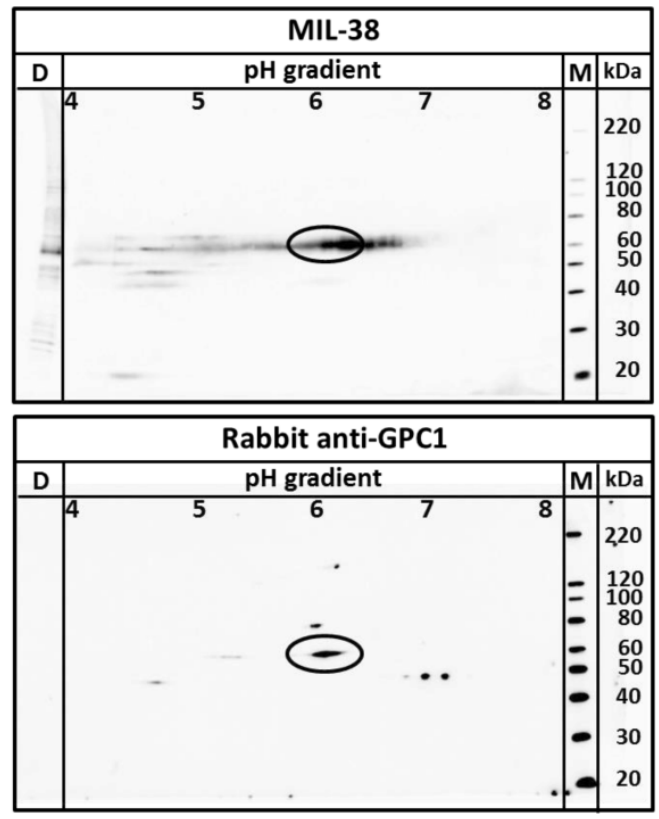

Figure 6. Two dimensional western blot using MIL-38 and rabbit anti-GPC-1 on DU-145 membrane protein extracts. The antigen identified by both antibodies overlap at $60 \mathrm{kDa}$ at isoelectric point 6 (indicated by ellipse).

Two dimensional electrophoresis was used to confirm MIL-38 and rabbit anti-GPC-1 recognised the same antigen in DU-145 protein extracts. As shown in Figure 6, MIL-38 antibody and the rabbit anti-GPC-1 antibodies showed overlapping reactivity detecting a protein with $60 \mathrm{kDa}$ molecular weight and isoelectric points ranging from 5 to 7 .

A commercially available recombinant GPC-1 protein was tested for reactivity with MIL-38 and rabbit anti-GPC-1 antibodies. This full-length GPC-1 was produced in murine NS0 cells. Strong reactivity of both MIL-38 and rabbit anti-GPC-1 antibodies with this protein was observed (Figure 7) under non-reducing conditions. Rabbit anti-GPC-1 was also able to react with the reduced form of the recombinant protein. The characterization and confirmatory results described all strongly suggest that the antigen is GPC-1.

\section{GPC-1 ELISA}

Our data indicates that a soluble form of GPC-1 can be detected in DU-145 conditioned medium. This suggests that the MIL-38 antibody may be useful in detecting soluble forms of GPC-1 in body fluids. Three MIL-38-based ELISA assay formats were used to test this (Figure 8). Recombinant GPC-1 was tested at $0,0.1,1$ and $10 \mathrm{ng} / \mathrm{ml}$ concentrations using MIL-38 as a capture antibody and rabbit anti-GPC-1 as a detection antibody. Similar experiments were conducted using the rabbit anti-GPC- 1 as the capture antibody and the MIL-38 as the detection antibody. A single antibody ELISA was also tested using the MIL-38 antibody as the capture antibody, and a biotinylated MIL-38 antibody as the detection antibody. All assay formats were able to detect recombinant GPC-1 indicating that MIL-38 is a suitable candidate for further ELISA development.

\section{Discussion}

GPC-1 belongs to a six member family of heparan sulfate proteoglycans (HSPGs) ${ }^{13}$ linked to the cell surface by a glycosylphosphatidylinositol (GP1) anchor ${ }^{14,15}$. The size of the glypican core protein is $60-70 \mathrm{kDa}^{16,17}$. The antigen target for MIL-38 was detected in two forms: a membrane bound cell surface form of 55-60 kDa and soluble secreted forms of 52 $\mathrm{kDa}$ and $40 \mathrm{kDa}$. This supports other findings which show cancer cells can shed GPC-1 into the tumor microenvironment $t^{18,19}$.

Another member of the family, Glypican-3 (GPC-3) is known to be processed in the Golgi apparatus to form an N-terminal $40 \mathrm{kDa}$ and a C-terminal $30 \mathrm{kDa}$ subunit which have been proposed as serological markers for early stage hepatocellular carcinoma ${ }^{20}$. When the protein is translocated to the cell surface, a second proteolytic event cleaves the GPI anchor to release the subunits. It is therefore reasonable to assume that GPC-1 could be similarly cleaved resulting in the observed $40 \mathrm{kDa}$ and $52 \mathrm{kDa}$ forms of GPC-1. 


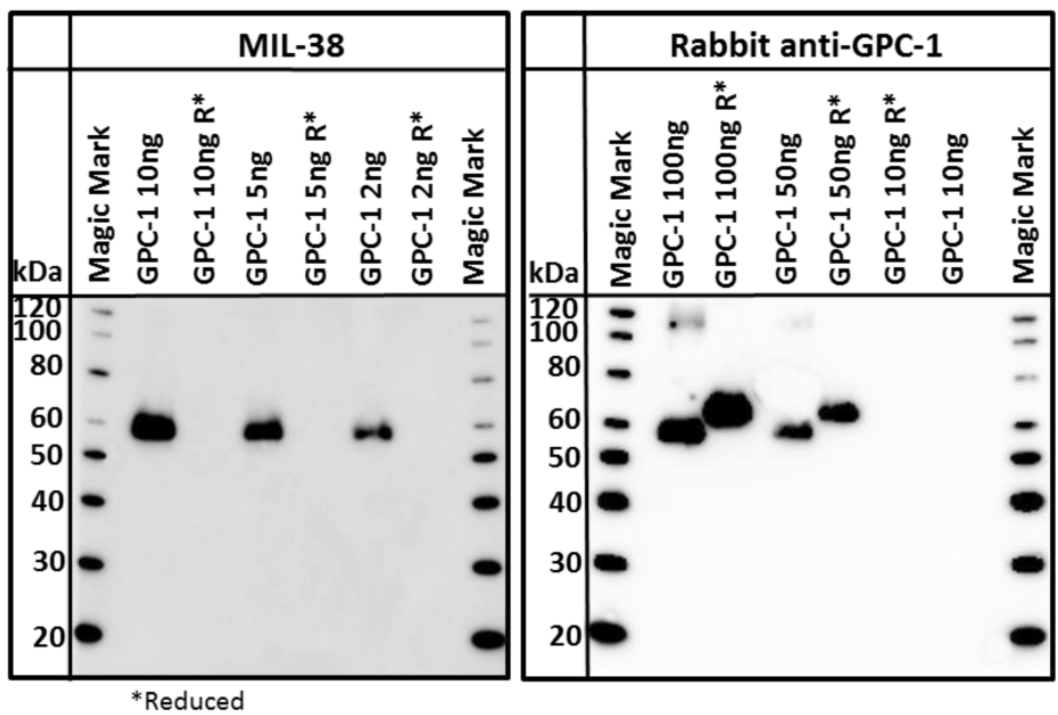

Figure 7. Western blot of recombinant GPC-1. Both MIL-38 and rabbit anti-GPC-1 recognize the same non reduced forms of the protein. Rabbit anti-GPC-1 can also recognize the reduced form of the protein. $R^{*}$ indicates that the sample was processed under reducing conditions.

A.

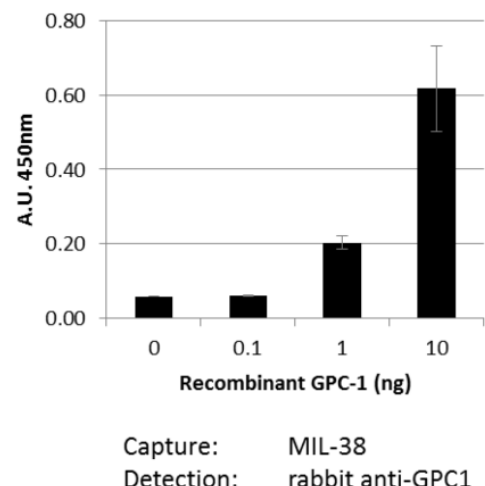

B

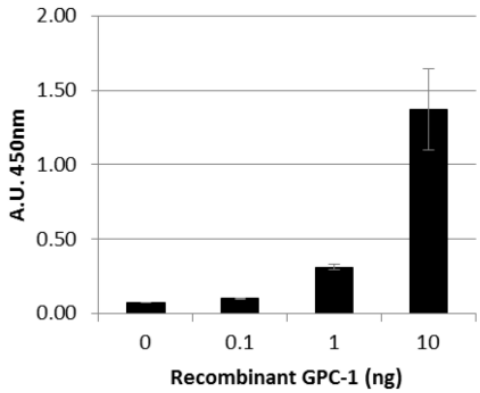

Capture: rabbit anti-GPC1 Detection: MIL-38

\section{C}

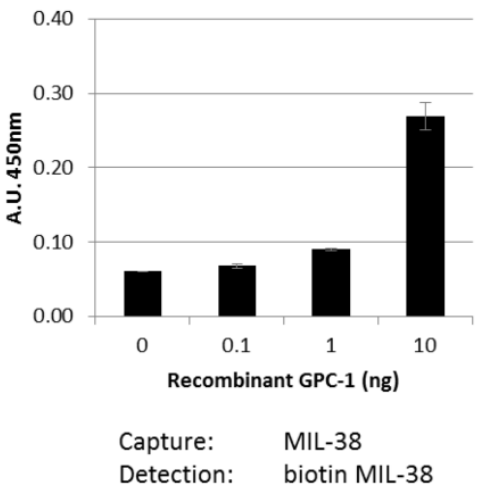

Figure 8. Bar graph showing various ELISA combinations of MIL-38 and rabbit anti-GPC-1. Recombinant GPC-1 was used as the analyte. All ELISA combinations show recombinant GPC-1 can be detected in a sandwich ELISA by MIL-38 as a capture antibody (A, C) and detector antibody (B, C).

Studies have shown glypicans have the ability to regulate the activity of growth and survival factors in tissue, suggesting glypicans play a role in cancer progression ${ }^{21}$. Reduced GPC-1 expression in pancreatic cell lines (PANC-1) has been shown to inhibit tumor progression 22 and reduced angiogenesis and metastasis ${ }^{23}$.

Of recent interest is the identification of GPC-1 on the surface of exosomes isolated from pancreatic cancer cell line PANC-124, breast cancer cell lines ${ }^{25}$ and prostate cancer cell lines ${ }^{26}$. Exosomes are secreted extracellular vesicles which contain the nucleic acids and protein information of the origin cell ${ }^{27,28}$ and are of interest regarding its role in immune response ${ }^{29}$, cell signalling ${ }^{30}$ cancer $^{31}$ and tumor progression ${ }^{32-34}$. It can be suggested that GPC-1 is a specific marker for cancer exosomes and could be used to identify cancer in patients.

GPC-1 is an attractive prostate cancer biomarker as it is present on the cell surface and also shed by the cells. It's identification on exosomes from blood and urine allows an avenue for targeted personalized therapy as the genetic and proteomic mutations are specific to the cancer patient. Future studies are underway to develop a MIL-38 based GPC-1 ELISA to assess the levels of GPC- 1 in normal, BPH and prostate cancer patients to determine whether secreted GPC-1 may represent a clinically relevant biomarker for prostate cancer diagnosis. Preliminary data presented at the 2015 American Urology Association supports GPC-1 as an unrelated candidate biomarker with improved specificity $(79 \%)$ over PSA ${ }^{35}$, thereby reducing false positive reporting and the need for unnecessary biopsies. Furthermore, MIL-38 labelled with alpha emitting radioactive isotopes is able to suppress the growth of human prostate cancer subcutaneous xenografts in vivo ${ }^{36}$ and also as a targeting antibody for tissue specific gene 
therapy delivery ${ }^{37}$. The authors are currently studying the effects of GPC-1 modulation in prostate cancer using molecular techniques to examine growth and invasiveness in in vitro and in vivo models. Therefore, MIL-38 and its antigen target show great potential as a theranostic agent and biomarker for the early detection and treatment of prostate cancer.

\section{Acknowledgements}

The authors would like to thank Professor Pamela Russell for providing the C3 cell lines and BLCA-38 hybridoma and the Australian Proteome Analysis Facility for mass spectrometric analysis.

\section{Conflict of Interest}

The authors declare no conflicts of interest. The authors are employed by and are shareholders in Minomic International Ltd.

\section{References}

1. Velonas VM, Woo HH, Remedios CGd, Assinder SJ. Current status of biomarkers for prostate cancer. International Journal of molecular sciences 2013; 14(6): 11034-11060.

2. Barry MJ. Screening for prostate cancer - the controversy that refuses to die. New England Journal of medicine 2009; 360(13): 1351-1354.

3. McNaughton-Collins MF, Barry MJ. One man at a time-resolving the PSA controversy. New England Journal of medicine 2011; 365(21): 1951-1953.

4. Dijkstra S, Mulders P, Schalken J. Clinical use of novel urine and blood based prostate cancer biomarkers: a review. Clinical biochemistry 2014; 47(10): $889-896$

5. Bratt $\mathrm{O}$, Lilja H. Serum markers in prostate cancer detection. Current opinion in urology 2015; 25(1): 59-64.

6. Ferro M, Bruzzese D, Perdona S, Marino A, Mazzarella C, Perruolo G et al. Prostate Health Index (Phi) and Prostate Cancer Antigen 3 (PCA3) significantly improve prostate cancer detection at initial biopsy in a total PSA range of 2-10 ng/ml. PLoS one 2013; 8(7): e67687.

7. Bryant RJ, Sjoberg DD, Vickers AJ, Robinson MC, Kumar R, Marsden L et al. Predicting high-grade cancer at ten-core prostate biopsy using four kallikrein markers measured in blood in the ProtecT study. Journal of the National Cancer Institute 2015; 107(7): djv095.

8. Alley SC, Okeley NM, Senter PD. Antibody-drug conjugates: targeted drug delivery for cancer. Current opinion in chemical biology 2010; 14(4): 529-537.

9. Senter PD. Potent antibody drug conjugates for cancer therapy. Current opinion in chemical biology 2009; 13(3): 235-244.

10. Russell PJ, Jelbart M, Wills E, Singh S, Wass J, Wotherspoon J et al. Establishment and characterization of a new human bladder cancer cell line showing features of squamous and glandular differentiation. International Journal of cancer 1988; 41(1): 74-82.

11. Walker KZ, Russell PJ, Kingsley EA, Philips J, Raghavan D. Detection of malignant cells in voided urine from patients with bladder cancer, a novel monoclonal assay. The Journal of urology 1989; 142(6): 1578-1583.

12. Russell PJ, Ow KT, Tam PN, Juarez J, Kingsley EA, Qu CF et al. Immunohistochemical characterisation of the monoclonal antibody BLCA-38 for the detection of prostate cancer. Cancer Immunology, Immunotherapy 2004; 53(11): 995-1004.

13. Perrimon N, Bernfield M. Specificities of heparan sulphate proteoglycans in developmental processes. Nature 2000; 404(6779): 725-728.

14. David G, Lories V, Decock B, Marynen P, Cassiman J-J, Van den Berghe H. Molecular cloning of a phosphatidylinositol-anchored membrane heparan sulfate proteoglycan from human lung fibroblasts. The Journal of cell biology 1990; 111(6): 3165-3176.

15. Chen RL, Lander AD. Mechanisms underlying preferential assembly of heparan sulfate on glypican-1. Journal of biological chemistry 2001; 276(10): 7507-7517.

16. Iozzo RV, Sanderson RD. Proteoglycans in cancer biology, tumour microenvironment and angiogenesis. Journal of cellular and molecular medicine 2011; 15(5): 1013-1031.

17. Svensson G, Awad W, Håkansson M, Mani K, Logan DT. Crystal Structure of N-Glycosylated Human Glypican-1 Core Protein structure of Two Loops Evolutionarily Conserved in Vertebrate Glypican-1. Journal of biological chemistry 2012; 287(17): 14040-14051.

18. Matsuda K, Maruyama H, Guo F, Kleeff J, Itakura J, Matsumoto $\mathrm{Y}$ et al. Glypican-1 is overexpressed in human breast cancer and modulates the mitogenic effects of multiple heparin-binding growth factors in breast cancer cells. Cancer research 2001; 61(14): 5562-5569.

19. Kleeff J, Ishiwata T, Kumbasar A, Friess H, Büchler MW, Lander AD et al. The cell-surface heparan sulfate proteoglycan glypican-1 regulates growth factor action in pancreatic carcinoma cells and is overexpressed in human pancreatic cancer. Journal of clinical investigation 1998; 102(9): 1662.

20. Hippo Y, Watanabe K, Watanabe A, Midorikawa Y, Yamamoto S, Ihara S et al. Identification of soluble NH2-terminal fragment of glypican-3 as a serological marker for early-stage hepatocellular carcinoma. Cancer research 2004; 64(7): 2418-2423.

21. Filmus J, Selleck SB. Glypicans: proteoglycans with a surprise. Journal of clinical investigation 2001; 108(4): 497-501.

22. Kleeff J, Wildi S, Kumbasar A, Friess H, Lander AD, Korc M. Stable transfection of a glypican-1 antisense construct decreases tumorigenicity in PANC-1 pancreatic carcinoma cells. Pancreas 1999; 19(3): 281-288.

23. Aikawa T, Whipple CA, Lopez ME, Gunn J, Young A, Lander AD et al. Glypican-1 modulates the angiogenic and metastatic potential of human and mouse cancer cells. The Journal of clinical investigation 2008; 118(1): 89.

24. Melo SA, Luecke LB, Kahlert C, Fernandez AF, Gammon ST, Kaye J et al. Glypican-1 identifies cancer exosomes and detects early pancreatic cancer. Nature 2015; 523: 177-182

25. Melo SA, Sugimoto H, O'Connell JT, Kato N, Villanueva A, Vidal A et al. Cancer exosomes perform cell-independent microRNA biogenesis and promote tumorigenesis. Cancer cell 2014; 26(5): 707-721.

26. Duijvesz D, Versluis CYL, van der Fels CA, Vredenbregt-van den Berg MS, Leivo J, Peltola MT et al. Immuno-based detection of extracellular vesicles in urine as diagnostic marker for prostate cancer. International Journal of cancer 2015; 137(12): 2869-2878.

27. Trajkovic K, Hsu C, Chiantia S, Rajendran L, Wenzel D, Wieland F et al. Ceramide triggers budding of exosome vesicles into multivesicular endosomes. Science 2008; 319(5867): 1244-1247.

28. Urbanelli L, Magini A, Buratta S, Brozzi A, Sagini K, Polchi A et al. Signaling pathways in exosomes biogenesis, secretion and fate. Genes 2013; 4(2): 152-170.

29. Théry C, Ostrowski M, Segura E. Membrane vesicles as conveyors of immune responses. Nature reviews immunology 2009; 9(8): 581-593.

30. Bobrie A, Colombo M, Raposo G, Théry C. Exosome secretion: molecular mechanisms and roles in immune responses. Traffic 2011; 12(12): 1659-1668.

31. Taylor DD, Gercel-Taylor C. Exosomes/microvesicles: mediators of cancer-associated immunosuppressive microenvironments. Seminars in immunopathology, 2011; 33(5): 441-454.

32. Skog J, Würdinger T, van Rijn S, Meijer DH, Gainche L, Curry WT et al. Glioblastoma microvesicles transport RNA and proteins that promote tumour growth and provide diagnostic biomarkers. Nature cell biology 2008; 10(12): 1470-1476.

33. Beckler MD, Higginbotham JN, Franklin JL, Ham A-J, Halvey PJ, Imasuen IE et al. Proteomic analysis of exosomes from mutant KRAS colon cancer cells identifies intercellular transfer of mutant KRAS. Molecular \& cellular proteomics 2013; 12(2): 343-355.

34. Janowska-Wieczorek A, Wysoczynski M, Kijowski J, Marquez-Curtis L, Machalinski B, Ratajczak J et al. Microvesicles derived from activated platelets induce metastasis and angiogenesis in lung cancer. International journal of cancer 2005; 113(5): 752-760.

35. Shore N, Concepcion R, Saltzstein D, Paivanas T, Beebe-Dimmer J, Ruterbusch $\mathrm{J}$ et al. Glypican-1 as a Biomarker for Prostate Cancer. The Journal of urology 2015; 193(4): e410-e411.

36. Li Y, Song E, Abbas Rizvi SM, Power CA, Beretov J, Raja C et al. Inhibition of micrometastatic prostate cancer cell spread in animal models by ${ }^{213}$ Bilabeled multiple targeted alpha radioimmunoconjugates. Clinical cancer research 2009; 15(3): 865-875.

37. Khatri A, Ho T, Lindholm L, Russell PJ. Promise of BLCA38 as a Targeting Antibody for Tissue-Specific Gene Delivery to Prostate Cancer. Austral-Asian Journal of cancer 2010; 9(3): 195-203. 